\title{
Examining changes in bat swing kinematics in different areas of the strike zone in collegiate baseball players
}

Charles C. Williams

Paul T. Donahue

Samuel J. Wilson

James Grant Mouser

Christopher M. Hill

See next page for additional authors

Follow this and additional works at: https://bearworks.missouristate.edu/articles-chhs

\section{Recommended Citation}

Williams, Charles C., Paul T. Donahue, Samuel J. Wilson, J. Grant Mouser, Christopher M. Hill, Lauren A. Luginsland, Jacob R. Gdovin, Chip Wade, and John C. Garner. "Examining Changes in Bat Swing Kinematics in Different Areas of the Strike Zone in Collegiate Baseball Players." International Journal of Kinesiology and Sports Science 8, no. 2 (2020): 1-6.

This article or document was made available through BearWorks, the institutional repository of Missouri State University. The work contained in it may be protected by copyright and require permission of the copyright holder for reuse or redistribution.

For more information, please contact BearWorks@library.missouristate.edu. 


\section{Authors}

Charles C. Williams, Paul T. Donahue, Samuel J. Wilson, James Grant Mouser, Christopher M. Hill, Lauren A. Luginsland, Jacob Gdovin, Chip Wade, and John C. Garner 


\section{Examining Changes in Bat Swing Kinematics in Different Areas of the Strike Zone in Collegiate Baseball Players}

Charles C. Williams ${ }^{1 *}$, Paul T. Donahue ${ }^{2}$, Samuel J. Wilson ${ }^{3}$, J. Grant Mouser ${ }^{4}$, Christopher M. Hill ${ }^{5}$, Lauren A. Luginsland ${ }^{6}$, Jacob R. Gdovin 7 , Chip Wade ${ }^{8}$, John C. Garner ${ }^{4}$

${ }^{1}$ Department of Clinical and Applied Movement Sciences; University of North Florida 1 UNF Drive, Jacksonville FL 32224

${ }^{2}$ School of Kinesiology and Nutrition; University of Southern Mississippi, 118 College Drive, Hattiesburg MS 39406 USA

${ }^{3}$ Department of Health Sciences and Kinesiology; Georgia Southern University 1332 Southern Drive, Statesboro GA 30458 USA

${ }^{4}$ Department of Kinesiology; Troy University 600 University Ave, Troy AL 36082 USA

${ }^{5}$ Department of Physical Education; Northern Illinois University 1425 Lincoln Hwy, DeKalb IL 60115 USA

${ }^{6}$ Department of Health, Exercise Science, and Recreation Management University, MS 38677 USA

${ }^{7}$ Department of Kinesiology; Missouri State University 901 South National Ave, Springfield MO 65897 USA

${ }^{8}$ Department of Kinesiology; Troy University 600 University Ave, Troy AL 36082 USA

Corresponding Author: Charles C. Williams, E-mail: c.williams@unf.edu

\section{ARTICLE INFO}

\section{Article history}

Received: January 21, 2020

Accepted: April 15, 2020

Published: April 31, 2020

Volume: 8 Issue: 2

Conflicts of interest: None

Funding: None

\begin{abstract}
Background: According to the National Collegiate Athletic Association (NCAA) there are over 34,000 athletes who compete in baseball at the collegiate level. These individuals spend countless hours training to improve their ability at bat performance by use of a batting tee and their position preference. However, during a game situation an athlete may swing a bat through their strike zone depending on the pitch thrown by an opposing pitcher. Objective: The aim of this investigation was to examine changes in swing kinematics throughout an individual's strike zone in collegiate baseball players. Variables of interest included resultant velocity at ball contact (RVBC) and the angle of the bat at ball contact (BABC). Methodology: A series of markers were placed on the tee and bat to record swing kinematic variables of interest. Participants completed a brief two-minute on-deck warm-up protocol before being counterbalanced into completing 15 swing trials in various regions of their respective strike zone. A ten-minute washout period was completed followed by another 15 swing trials throughout their strike zone until there was a total of 45 swing trials, having 5 swing trials completed in each of the nine regions of the strike zone. Results: Repeated measures analysis of variance were used to examine swing kinematic variables of interest. Significant differences were found in RVBC along with significant differences in BABC $(\mathrm{p}<.05)$. Conclusions: Knowledge of this information can allow both athlete and sport coach to identify areas of weakness when addressing their hitting performance in preparation for an at bat situation during a game.
\end{abstract}

Key words: Sports, Velocity, Performance, Baseball, Biomechanics

\section{INTRODUCTION}

The National Collegiate Athletic Association estimates there are over 34,000 baseball athletes competing at the collegiate level (National Collegiate Athletic Association 2018). Evidence based literature has examined a variety of areas intended to maximize batting performance in terms of bat speed as it has been shown to be an important predictor of a batter's performance as they attempt to make contact with a ball (Scott, 1942). Another important aspect of batting performance is the angle of the bat as the athlete approaches contact with the ball. Changes in the angle of the bat allows the athlete to make better contact, which in turn could lead to a greater likelihood of success during an at bat. To date, there are several research designs that have examined bat swing kinematics (Escamilla et al., 2009a, 2009b; Williams et al., 2019).

Previous work by Welch et al. (1995) and Escamilla et al. (2009a) wanted to investigate the effects of an individual's stance and stride on batting performance specifically that of bat speed in high baseball athletes. Welch et al. (1995) utilized professional baseball players and they discovered the longer they spent during the stride phase of the swing lead to an increase in bat swing velocity $(\mathrm{p}<.05)$ (Welch, Banks, Cook, \& Draovitch, 1995). Work by Escamilla et al. (2009a) examined age-related difference in baseball hitting kinematics among youth and professional baseball players. A total 
of 24 players participated in this study that all had a batting average of at least .300 classifying them as skilled athletes based on previous research (DeRenne, Morgan, Hetzler, \& Taura, 2008; Escamilla et al., 2009a; Race, 1961). Participants were asked to swing at balls thrown towards the inner half of the participant's strike zone establishing a standardized pitch. Results of this study indicated the older adult hitters spent more time during the stride phase of the swing $0.4 \pm .07$ seconds in comparison to youth hitters at $0.29 \pm .06$ seconds $(p<.01)$. The extended time during the stride phase of the swing allowed the adult hitters to generate a greater bat velocity at ball contact at $30 \pm 2 \mathrm{~m} / \mathrm{s}$ in comparison to $25 \pm 3 \mathrm{~m} / \mathrm{s}$ for youth hitters $(p<.01)$ (Escamilla et al., 2009a).

A recent investigation by Williams et al. (2019) examined the acute changes in bat swing kinematics after collegiate baseball players warmed up with a variety of weighted implements. Participants were counter-balanced into completing one of four warm-up (WU) protocols with either a heavy, normal, or light-weight condition. Results of this study revealed no statistical differences among WU implements in swing velocity; however, there were significant intra-class correlation coefficients (ICC's) among the WU implements. This suggests that collegiate baseball players can produce a similar bat speed and angle at contact regardless of the WU implement used on-deck (Williams et al., 2019).

Previous research designs have examined bat swing kinematics by asking participants to swing at a pitched ball in a position convenient for them or swinging of a tee in a position of their choosing (Escamilla et al., 2009a; Messier \& Owen, 1984, 1985; Williams et al., 2019) to standardize each trial. Unfortunately, this is may not be realistic to the situations seen during games as pitches are thrown in a variety of locations and different speeds throughout the strike zone. The NCAA defines the strike zone as an area covering the entire width of home plate and a region extending from a batter's knee cap and extends to below the area of their number as he or she sets up in their respective stance (Paronto, 2014). The strike zone can be broken into nine distinct locations and three distinct zones. To the authors knowledge, examination of swing kinematics across the strike zone have not been completed. Common batting practices utilize a tee which an athlete can place at various heights to practice at making ball contact within varying locations of their strike zone. This study can provide both coaches and athletes information regarding their batting performance in terms of maximizing bat speed and angle at the time of ball contact.

The primary aim of this investigation was to examine changes in bat swing kinematics within the nine locations and three zones of an athlete's strike zone, specifically resultant velocity at ball contact (RVBC). A secondary aim of this study was to examine the angle of the bat at ball contact within the nine locations of their respective strike zone.

\section{METHODOLOGY}

\section{Participants and Design of Study}

Thirteen (age:19.69 \pm 1.18 years, height: $184 \pm 6.16 \mathrm{~cm}$, mass: $93.32 \pm 9.8 \mathrm{~kg}$ ) division I baseball players participated in the study. The aim of this experimental design was to investigate changes in RVBC along with BABC across the nine regions of an individual's strike zone as they are indicators of hitting performance (Escamilla et al., 2009a; Scott, 1942; Williams et al., 2019). Participants were free from musculoskeletal injuries after filling out a physical readiness questionnaire (PAR-Q). To ensure accurate kinematic measures of interest we wanted to make sure that all participants were healthy to ensure accurate measures. Participants who were not deemed healthy based on their responses to the PAR-Q were excluded from the study. Prior meetings with both sport coaches and athletes took place to become aware of the potential benefits and risks of completing the current study. Participants signed a University informed consent and the study was approved by the Institutional Review Board (IRB) protocol number 16-017.

\section{Procedures}

The current study compared how bat swing kinematics changed throughout an individual's respective strike zone in high level collegiate baseball players. A motion capture system equipped with 8 near-infrared T-Series cameras recorded all kinematic variables of interest. Motion capture systems have been a reliable instrument measuring kinematic variables in previous biomechanics research (Bonnechere et al., 2014; Fleisig, Zheng, Stodden, \& Andrews, 2002; Milanovich \& Nesbit, 2014; Tsushima, Morris, \& McGinley, 2003; Williams et al., 2019). A custom bat and tee model were used to measure swing kinematics of interest along with a modified, full-body Helen Hayes marker system for a total of 47 retro-reflective markers (Figure 1) sampling at $200 \mathrm{~Hz}$. In order to quantify $3 \mathrm{D}$ motion, a global coordinate system was employed to best record the trajectories of the individual markers affixed to the bat. The X-direction was defined as the vector in which all participants swung their bat as they approached contact with a ball towards home plate. The Z-direction was defined as the vertical projection upward. The cross-product of the $\mathrm{X}$ and $\mathrm{Z}$ directions were used to define the Y-direction. The aforementioned definitions of the global

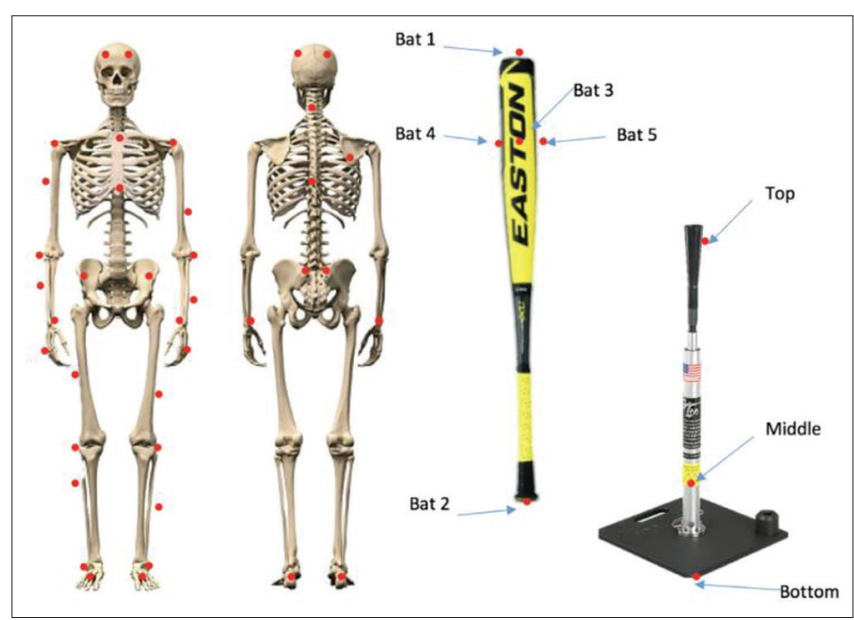

Figure 1. Modified Helen Hayes full body marker system and custom made bat and tee marker locations, ( $\mathbf{0}$ ) represent retroreflective markers 
coordinate system have been used in previous investigations (Escamilla et al., 2009a; Williams et al., 2019).

Procedures for this study design utilized a traditional hitting tee and standard bat (SB) which must not weigh more than three units than the length of the bat. A SB is either 33in $130 \mathrm{oz}$ or $34 \mathrm{in} / 31 \mathrm{oz}$ at the collegiate level (Paronto, 2014). Participants used either a $33 \mathrm{in} / 30 \mathrm{oz}$ or $34 \mathrm{in} / 31 \mathrm{oz}$ bat based on what they used in practice or game situations. Participants came in for one experimental session after being informed of all the benefits and risks prior to signing documentation prior to completing the study. Each participant was asked to maintain their normal activities of daily living prior and came to the lab prior to fall practice. Anthropometrics measurements were taken on all participants prior to testing. After measurements were recorded, participants had a total of 39 retro-reflective markers secured to specific anatomical landmarks.

A counterbalanced design was used to determine the tee position for each participant as each participant will have a different strike zone based on their height. In order to make each strike zone relative to each participant, the bottom of the strike zone was defined as the region above the kneecap once the participant set up in their respective stance. The top of their strike zone was defined as 6 inches above each participant's belt line which represents the bottom of the number on a jersey. The middle of their strike zone is the middle distance between the top and bottom of each participant's strike zone. For tee positions located at the bottom and top of their respective strike, we asked each participant whether or not they would swing at a ball pitched into this specific location with two strikes against them in a game situation to confirm an appropriate tee location for each participant. Considering the strike zone covers the entire width of home plate, the tee was placed in different regions of home plate mimicking bat placement for an inside, middle, or outside pitch in a game situation (Figure 2). The locations for tee placement over the strike zone were based on how the sport coach taught the athletes to swing based on a given pitch. The following nine locations of the strike zone are as follows: inside high (IH), inside center (IC), inside low (IL), middle high (MH), middle center $(\mathrm{MC})$, middle low $(\mathrm{ML})$, outside high $(\mathrm{OH})$, outside center (OC), and outside low (OL) (Figure 3).

Once this was determined, each participant completed a 2 minute on-deck WU mimicking what they would do prior to an at bat situation in a game with their SB. After the WU, a short rest period took place allowing each participant the opportunity to set-up for each swing trial. Each participant was asked to set-up in their respective batting stance as they would in a game situation. By doing this, participants could not adjust to where the tee was located within home plate. Participants were asked to swing their SB at a baseball placed on a tee in a random position of their strike zone. Each swing was separated by a period of 20 seconds to mimic the time between pitches. At the conclusion of the $15^{\text {th }}$ swing, a ten-minute washout period was implemented followed by another 15 swing trials. This was repeated until there was a total of five swing trials within the nine regions of each participant's strike zone totaling 45 trials.

\section{Data Analysis}

Each swing trial was divided into three distinct phases and four specific events based on previous work by Shaffer et al. (1993) and Escamilla et al. (2009). The first event began when each participant's lead (stride) foot left the ground, which started the stride phase of the swing. The stride phase ended when the lead toe reestablished contact with the ground representing the $2^{\text {nd }}$ event of the swing. The point at which the lead foot reestablishes contact with the ground up to the point where the bat reaches a perpendicular position with the ground $\left(3^{\text {rd }}\right.$ event) represents the transition phase of the swing (Escamilla et al., 2009a; Shaffer, Jobe, Pink, \& Perry, 1993). The swing phase begins when the bat is perpendicular with the ground and ended when bat-ball contact was made (Escamilla et al., 2009a; Shaffer et al., 1993) which was defined as the frame in which deformation of the tee occurred when bat-ball contact was made (Williams et al., 2019).

RVBC was determined by squaring the sum of squares based on positional marker data for $\mathrm{X}, \mathrm{Y}$, and $\mathrm{Z}$ directions of the frame where deformation of the tee occurred from the bat as it made contact with the ball. A global coordinate system was put in place to determine overall movement of all hitting variables of interest. In order to track BABC, the global coordinate system was translated to the top of the tee which represented a relative $0^{\circ}$ to represent ground level. A custom bat model was used to track where the angle of the bat at these distinct frames where bat-ball contact occurred along with RVBC (Williams et al., 2019).

\section{Statistical Analysis}

Results were analyzed using SPSS 22 statistical software with a predetermined alpha level of 0.05 using a 1(condi-

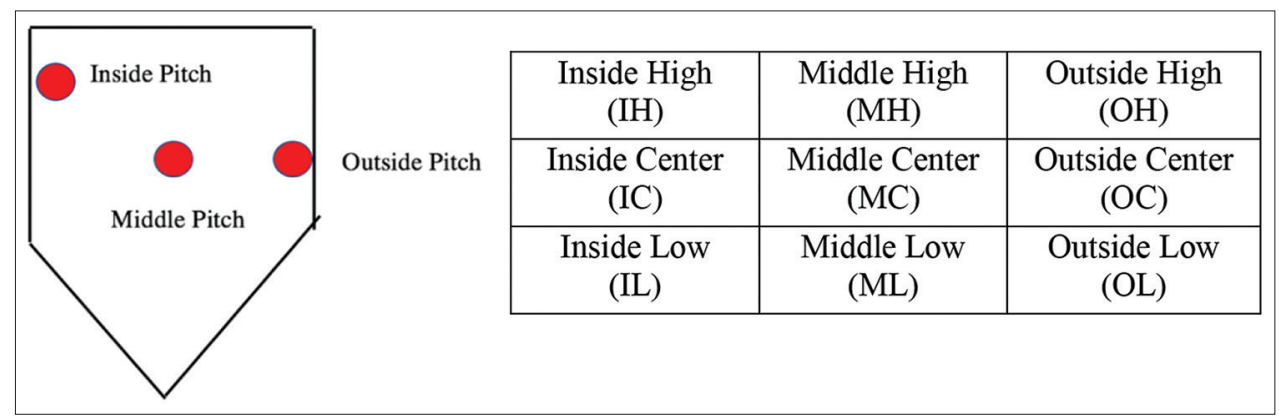

Figure 2. Tee position for inside, middle and outside zone and swing location for a right-handed batter 
tion) x 9 (locations of strike zone) within subject's factor repeated measures analysis of variance (ANOVA) on all swing kinematic variables of interest. Two additional $3 \times 3$ ANOVAs were performed to determine zone and height differences in looking at RVBC and BABC. If sphericity was violated, Mauchly's test of sphericity and a Greenhouse-Geisser correction was used as needed. If a significant main effect was found, Fisher's LSD was used to determine pairwise comparisons among the variables of interest.

\section{RESULTS}

There was not a significant main effect regarding RVBC across the nine locations of the strike zone (F(.133, 4.064 $\mathrm{p}=.07)$. Pairwise comparisons revealed trials completed $\mathrm{IH}$ of one's strike zone yielded a faster RVBC $(37.16 \pm .693 \mathrm{~m} / \mathrm{s})$ in comparison to $\mathrm{OH}$ swing trials $(35.70 \pm .85 \mathrm{~m} / \mathrm{s})(\mathrm{p}=.007)$.

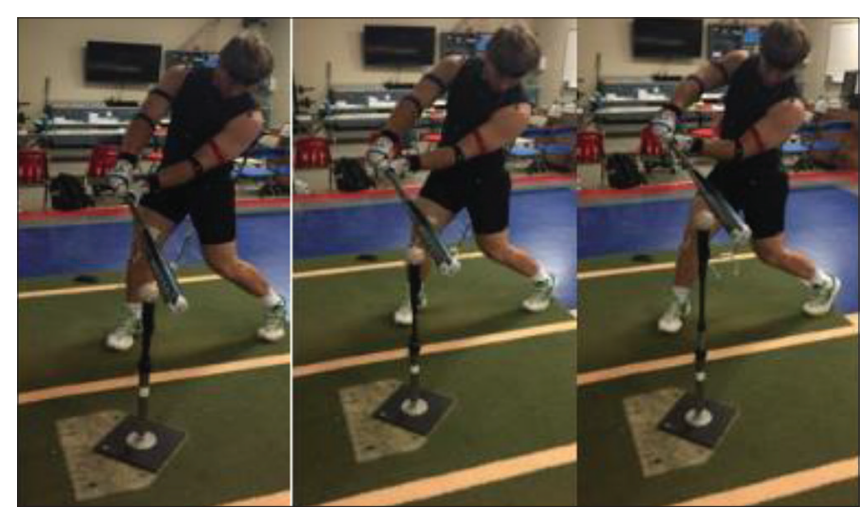

Figure 3. Individual swing trial at various heights mimicking swing trials completed in the middle zone at varying locations: middle low, middle center, middle high
IC swing trials had a faster RVBC $(37.62 \pm .67 \mathrm{~m} / \mathrm{s})$ in comparison $\mathrm{MH}:(35.51 \pm .89 \mathrm{~m} / \mathrm{s})(\mathrm{p}<.01), \mathrm{OH}(35.70 \pm .85 \mathrm{~m} / \mathrm{s})$ $(p=.023)$, OC $(35.97 \pm 79 \mathrm{~m} / \mathrm{s})(\mathrm{p}=.029)$, OL $(35.85 \pm .833 \mathrm{~m} / \mathrm{s})$ $(\mathrm{p}=.040)$. IL swing trials also exhibited a faster RVBC $(37.47 \pm .67 \mathrm{~m} / \mathrm{s})$ in comparison to $\mathrm{MH}:(35.51 \pm .89 \mathrm{~m} / \mathrm{s})$ $(\mathrm{p}<.05)$ and $\mathrm{OH}(35.70 \pm .85 \mathrm{~m} / \mathrm{s})(\mathrm{p}<.05)$.

There was also a significant main effect for RVBC regarding zone $(\mathrm{F}(.291,13.383, \mathrm{p}=.001)$ where swing trials took place. Pairwise comparisons revealed trials completed over the inside portion of the strike zone $(37.42 \pm .6 \mathrm{~m} / \mathrm{s})$ of the strike zone was significantly faster in comparison to the middle $(36.21 \pm .77 \mathrm{~m} / \mathrm{s})(\mathrm{p}=.007)$ and outside zone $(35.84 \pm .61 \mathrm{~m} / \mathrm{s})(\mathrm{p}=.001)$ of their respective strike zone at bat-ball contact. There were no significant main effects when looking at RVBC among the three different heights $(\mathrm{p}>.05)$.

Our results also revealed a significant main effect regarding BABC for both zone $(\mathrm{F}(.388,8.67, \mathrm{p}=.005)$ and height ( $\mathrm{F}(.104,47.42, \mathrm{p}<.01)$, (Figure 4 ) but yielded no significant interaction $(\mathrm{p}>.05)$. Pairwise comparisons revealed a greater mean bat angle for trials completed for inside zone swing trials $\left(57.27 \pm 3.1^{\circ}\right)$ in comparison to middle $\left(48.61 \pm 3^{\circ}\right)$ and outside portions of the strike zone $\left(48.23 \pm 3.5^{\circ}\right)(\mathrm{p}<.05)$. Significant differences were also seen in height, as the greatest angle at BABC was seen in swing trials completed in the bottom of their respective strike zone $\left(58.40 \pm 2.5^{\circ}\right)$ in comparison to swing trials completed in the center $\left(52.08 \pm 3.2^{\circ}\right)$ and high portions of their respective strike zone $\left(43.63 \pm 2.9^{\circ}\right)$ $(\mathrm{p}<.05)$.

Results also revealed a significant main effect of $\mathrm{BABC}$ among the nine distinct locations within a collegiate baseball players' strike zone $(\mathrm{F}(.05,11.92, \mathrm{p}=.007)$. Significant pairwise comparisons across the nine locations of the strike zone can be seen in Figure $5(\mathrm{p}<.05)$.

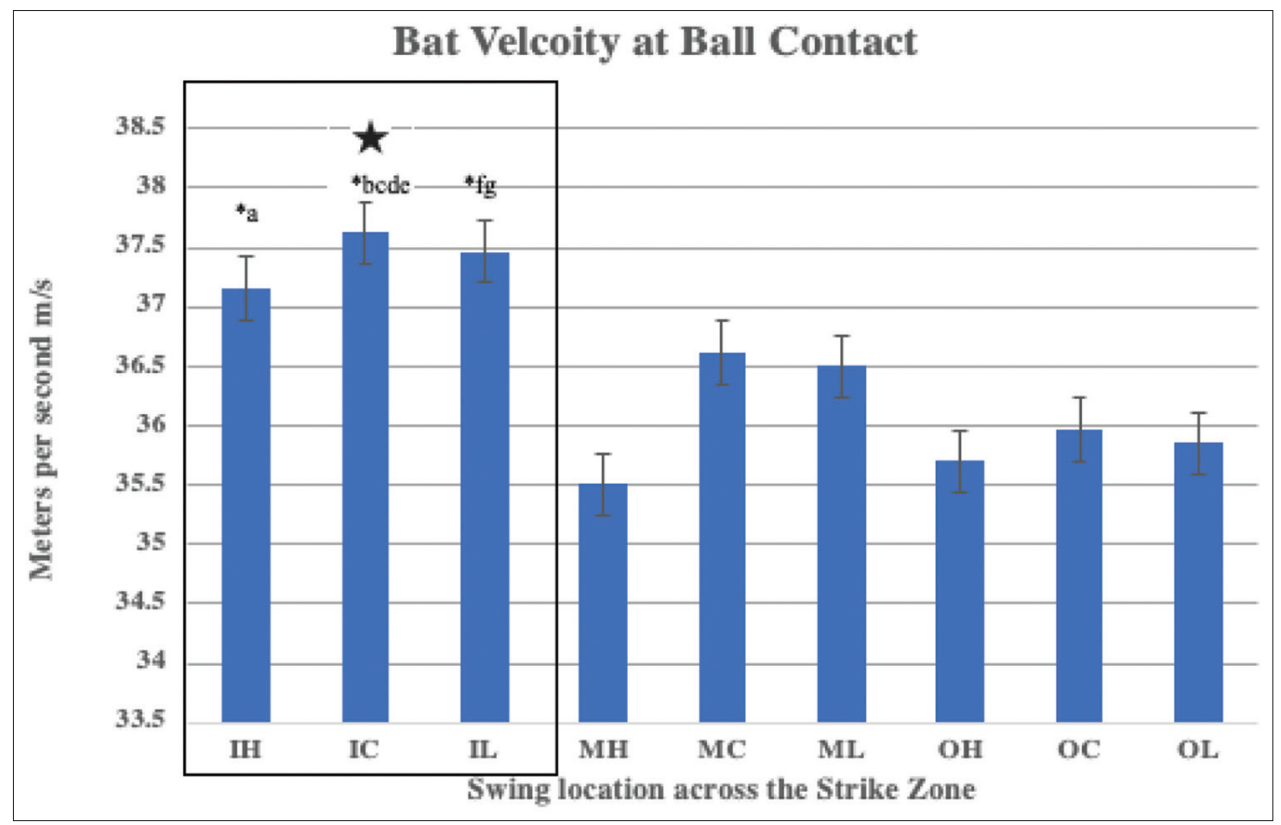

Figure 4. Changes in RVBC across location within the strike zone

(*) Significant Difference $(\mathrm{p}<.05)$ across swing location within strike zone

( $\star$ ) Significant Difference $(\mathrm{p}<.01)$ across Zon

Significant Post-hoc comparisons (p<.05) across location: ${ }^{a} \mathrm{IH} \& \mathrm{OH},{ }^{\mathrm{b}} \mathrm{IC} \& \mathrm{MH},{ }^{\mathrm{c} I C} \&$ OH, ${ }^{\mathrm{d} I C} \& O C,{ }^{\mathrm{e} I C} \&$ OL, ${ }^{\mathrm{f} I L} \& \mathrm{MH},{ }^{\mathrm{g}} \mathrm{IL} \& O H$ 


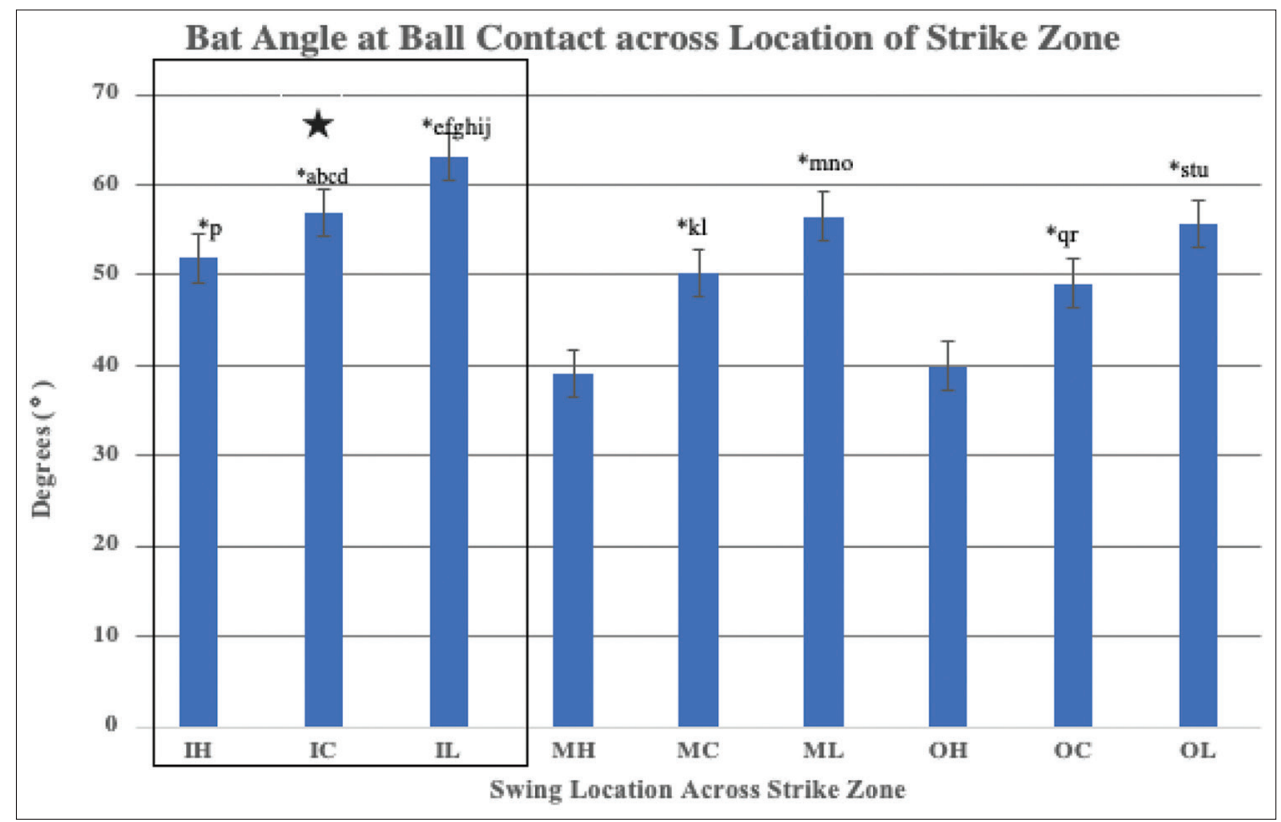

Figure 5. Bat angle at ball contact across strike zone and location in collegiate baseball players.

$(\star)$ Represents significant difference across zone $(\mathrm{p}<.05)$

(*) Significant Post-hoc comparisons among location (p<.05): ${ }^{\mathrm{I}} \mathrm{IC} \& \mathrm{IH},{ }^{\mathrm{b}} \mathrm{IC} \& \mathrm{MH}{ }^{\mathrm{c}} \mathrm{IC} \& \mathrm{MC}{ }^{\mathrm{d}} \mathrm{IC} \& O H{ }^{\mathrm{e}} \mathrm{IL} \& \mathrm{IH}{ }^{\mathrm{f}} \mathrm{IL} \& \mathrm{IC}{ }^{\mathrm{g}} \mathrm{IL} \& \mathrm{MH}$

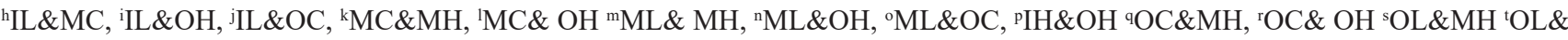
$\mathrm{OH}{ }^{\mathrm{u}} \mathrm{OL} \& \mathrm{OC}$

\section{DISCUSSION}

The aim of this investigation was to investigate changes in bat swing kinematics at bat-ball contact over an athlete's strike zone. Examining changes in RVBC, our current study reveals significant differences across the nine locations and across the three zones of the strike zone in collegiate baseball players. The three fastest velocities of the bat occurred towards the three inside locations of the strike zone in the following order: IC: $(37.62 \pm .67 \mathrm{~m} / \mathrm{s})$, IL $(37.47 \pm .67 \mathrm{~m} / \mathrm{s})$ and $\mathrm{IH}(37.16 \pm .693 \mathrm{~m} / \mathrm{s})$ in comparison to swing locations within the middle and outside portion of the strike zone $(\mathrm{p}<.05)$. Swing trials completed within the inside zone of their respective strike zone yielded the greatest RVBC in comparison to the middle and outside zones $(\mathrm{p}<.05)$.

Our study aligns with previous work completed by McIntyre and Pfautsch (1982) when looking at the RVBC in collegiate baseball players. McIntyre and Pfautsch (1982) investigated kinematic differences in same field hitting and opposite field hitting in collegiate baseball players. They defined same field hitting as a ball pitched towards the inside half of home plate towards the athlete swinging the bat which represents all middle and inside swing trials for the current study. Opposite field hitting represented a ball being pitched from the outside half of home plate representing the outside swing trials in the current study. They found the greatest bat velocity occurred at $42.2 \mathrm{~m} / \mathrm{s}$ for same side hitting in comparison to $39.3 \mathrm{~m} / \mathrm{s}$ for opposite field hitting (Mcintyre \& Pfautsch, 1982). The current study had the greatest velocity at ball contact at $(37.42 \pm .6 \mathrm{~m} / \mathrm{s})$ for trials completed on the inside zone of their home plate in comparison to swing trials completed on the outside of their strike zone $(35.84 \pm .61 \mathrm{~m} / \mathrm{s})$ $(\mathrm{p}=.001)$. Considering the tee was placed towards the inside of each participant's strike zone allows the batter a greater amount of time to complete the entire swing motion and therefore maximize linear velocity of the bat through ball contact. If a batter has to swing at a ball towards the outside corner of their respective strike zone, they have to square the bat up to make contact shortening the overall swing path. This leads to a decrease in swing velocity as seen in the Mcintyre and Pfautsch (1982) investigation and in the current study.

Our study does not align with the bat linear velocity values reported by Escamilla et al. (2009a). Results of their study revealed bat linear velocity trials collected was at an average velocity of $30 \mathrm{~m} / \mathrm{s}$ in the adult hitters. Participants in this study played at either the collegiate or professional level. Across all regions of the strike zone, the mean velocity was greater in the present study that was seen by Escamilla et al (2009a). Differences in these results could be based on the current study which asked participants to make contact with a ball placed on a tee in varying locations of the strike zone. Work by Escamilla et al. (2009a) asked participants to swing at a ball from a pitching machine possibly explaining differences in results as these participants had to react to a ball leading to ball contact (Escamilla et al., 2009a).

This is the first study to our knowledge that has examined changes in BABC in collegiate baseball players. Our study revealed that the swing trials performed towards the top of their respective strike zone had a lower angle considering the top of the tee represented a relative $0^{\circ}$ with the ground. Lower tee positions represented swing trials in the middle and bottom of their strike zone caused the barrel of the bat to have a more downward angle of at ball contact as seen in the current study. This study lays the ground work in quantifying bat angle at ball contact with what the eye 
sees during coaching and training sessions. The practical implication of this study can help coaches across the country objectively identify an appropriate angle of the bat as an individual approaches contact with a ball. In maximizing the surface area of the bat will increase the likelihood of ball contact with the hope of making a successful hit during a game situation

Considering this is one of the first studies to examine the barrel angle of the bat at ball contact, one primary limitation that may have affected the results was the sample size. Research involving athletic populations greatly reduces the available participant pool to have an ideal sample for this type of study in comparison to other study designs. It is also important to consider there are a wide variety of coaching techniques implemented throughout collegiate baseball and other hitting strategies could be used outside of what the current participants were taught by their respective sport coaches bringing to light the need to continue this line of research. Future research studies should continue to examine the angle of the bat at ball contact to further solidify our current work with populations of varying age and skill level.

\section{CONCLUSION}

It is evident that hitting kinematics change in different areas of the strike zone when looking at the velocity of the bat at ball contact. Both athlete and sport coaches can use this data to work on hitting technique and maximize bat velocity at ball contact in strike zone locations they are deficient in. This information can also be used to establish what would be considered an ideal bat angle for baseball, so both sport coaches and athletes can practice achieving the ideal bat angle in a given region of the strike zone during scheduled practice times. In doing, an athlete can maximize the overall surface area of the bat for ball contact to increase the likelihood of making contact with a ball.

\section{REFERENCES}

Bonnechere, B., Jansen, B., Salvia, P., Bouzahouene, H., Omelina, L., Moiseev, F.,... Jan, S. V. S. (2014). Validity and reliability of the Kinect within functional assessment activities: comparison with standard stereophotogrammetry. Gait \& posture, 39(1), 593-598. doi:https:// doi.org/10.1016/j.gaitpost.2013.09.018

DeRenne, C., Morgan, C., Hetzler, R. K., \& Taura, B. T. (2008). National and state youth baseball coaching requirements: a state case study. The Sport Journal, 11(2).

Escamilla, R. F., Fleisig, G. S., DeRenne, C., Taylor, M. K., Moorman, C. T., Imamura, R.,... Andrews, J. R. (2009a). A comparison of age level on baseball hitting kinematics. Journal of applied biomechanics, 25(3), 210-218. doi:https://doi.org/10.1123/jab.25.3.210

Escamilla, R. F., Fleisig, G. S., DeRenne, C., Taylor, M. K., Moorman, C. T., Imamura, R.,... Andrews, J. R. (2009b). Effects of bat grip on baseball hitting kine- matics. Journal of applied biomechanics, 25(3), 203209. doi:https://doi.org/10.1123/jab.25.3.203

Fleisig, G., Zheng, N., Stodden, D., \& Andrews, J. (2002). Relationship between bat mass properties and bat velocity. Sports Engineering, 5(1), 1-8. doi:https://doi. org/10.1046/j.1460-2687.2002.00096.x

Mcintyre, D. R., \& Pfautsch, E. W. (1982). A kinematic analysis of the baseball batting swings involved in opposite-field and same-field hitting. Research Quarterly for Exercise and Sport, 53(3), 206-213. doi:https://doi. org/10.1080/02701367.1982.10609341

Messier, S. P., \& Owen, M. G. (1984). Bat dynamics of female fast pitch softball batters. Research Quarterly for Exercise and Sport, 55(2), 141-145. doi:https://doi.org/1 0.1080/02701367.1984.10608390

Messier, S. P., \& Owen, M. G. (1985). Ground reaction forces and selected lower extremity kinematics during batting. Medicine \& Science in Sports \& Exercise, 17(2), 221-222. doi:https://doi.org/10.1080/02701367.1985.10 608448

Milanovich, M., \& Nesbit, S. M. (2014). A three-dimensional kinematic and kinetic study of the college-level female softball swing. Journal of sports science \& medicine, 13(1), 180.

National Collegiate Athletic Association. (2018). Estimated probability of competing in college athletics. (2018). Retrieved from http://NCAA.org

Paronto, J. (2014). NCAA Baseball: 2015 and 2016 Rules. In: The National Collegiate Athletic Association, Indianapolis, IN.

Race, D. E. (1961). A cinematographic and mechanical analysis of the external movements involved in hitting a baseball effectively. Research Quarterly. American Association for Health, Physical Education and Recreation, 32(3), 394-404. doi:http://dx.doi.org/10.1080/106 71188.1961 .10613161

Scott, M. G. (1942). Analysis of human motion: A textbook in kinesiology: Ardent Media.

Shaffer, B., Jobe, F. W., Pink, M., \& Perry, J. (1993). Baseball batting. An electromyographic study. Clinical orthopaedics and related research(292), 285-293.

Tsushima, H., Morris, M. E., \& McGinley, J. (2003). Test-retest reliability and inter-tester reliability of kinematic data from a three-dimensional gait analysis system. Journal of the Japanese Physical Therapy Association, 6(1), 9-17. doi:https://doi.org/10.1298/jjpta.6.9

Welch, C. M., Banks, S. A., Cook, F. F., \& Draovitch, P. (1995). Hitting a baseball: A biomechanical description. Journal of Orthopaedic \& Sports Physical Therapy, 22(5), 193-201. doi:10.2519/jospt.1995.22.5.193

Williams, C. C., Gdovin, J. R., Wilson, S. J., Cazas-Moreno, V. L., Eason, J. D., Hoke, E. L.,... Garner, J. C. (2019). The Effects of Various Weighted Implements on Baseball Swing Kinematics in Collegiate Baseball Players. The Journal of Strength \& Conditioning Research, 33(5), 1347-1353. doi:10.1519/jsc.0000000000002020 